\title{
A VisÃo REVISAdA DE MCDOWELL ACERCA DA EXPERIÊNCIA Perceptual E A AMEAÇA dA “ANsiedade Pluralista”
}

\author{
McDowell's Revised View of Perceptual Experience and the Threat of the "Pluralism ANXiety"
}

\author{
NAiAna dos Anjos, José Frota, Federico SAnguinetTi \\ Universidade Federal do Rio Grande do Norte (UFRN), BRASIL \\ naianjoslustosa@gmail.com,zefrota2015@icloud.com, sanfede@hotmail.it
}

\begin{abstract}
In his essay Avoiding the Myth of the Given (AMG), McDowell gives a new characterization both of the content of perceptual experience and of the way in which it enables a subject to know. This new characterization has been charged to give rise to a "pluralism anxiety". The goal of this paper is to explore in detail possible problems linked with the pluralism that arise from McDowell's change of mind about the content of perceptual experience, and to evaluate whether McDowell has conceptual resources to avoid them. The structure of the paper will be the following: first we will reconstruct in detail McDowell's revised view on perceptual experience as it is presented in AMG; then, we will reconstruct arguments in support of the claim that McDowell's revised position could give rise to a pluralism anxiety; finally yet importantly we will discuss whether it is possible to offer an interpretation of McDowell's position which offers a way out of such difficulties.
\end{abstract}

Key Words: Perceptual experience $\bullet$ McDowell $\bullet$ conceptualism $\bullet$ pluralism.

Essas ambiguidades, redundâncias e deficiências lembram aquelas que o doutor Franz Kuhn atribui a certa enciclopédia chinesa intitulada Empório Celestial de Conhecimentos Benévolos. Em suas remotas páginas consta que os animais se dividem em (a) pertencentes ao Imperador, (b) embalsamados, (c) amestrados, (d) leitões, (e) sereias, (f) fabulosos, (g) cães soltos, (h) incluídos nesta classificação, (i) que se agitam como loucos, (j) inumeráveis $(\mathrm{k})$ desenhados com um finíssimo pincel de pelo de camelo, (l) etecetera, (m) que acabam de quebrar o vaso, (n) que de longe parecem moscas.

Borges, O idioma analítico de John Wilkins

\section{Introdução}

Em seu ensaio Avoiding the Myth of the Given (AMG), John McDowell efetua duas mudanças à visão da experiência perceptual tal como ela foi exposta em Mente $e$ 
mundo (MM): ${ }^{1}$ primeiro, ele rejeita a tese segundo a qual as experiências possuem um conteúdo proposicional (i); segundo, ele rejeita a tese de que o conteúdo da experiência deve incluir tudo aquilo que a experiência permite que o sujeito conheça não inferencialmente (ii). Em AMG o autor traz, portanto, uma nova caraterização do conteúdo da experiência perceptual e do modo através do qual tal conteúdo possibilita ao sujeito conhecer. Essa nova caraterização da experiência perceptual tem sido acusada de gerar uma ansiedade pluralista (Corti, 2017).

Com isso em consideração, podemos passar aos objetivos do presente artigo, quais sejam: considerar, tendo em vista a discussão do artigo de Luca Corti (2017), algumas possíveis dificuldades ligadas ao pluralismo que surgem a partir da virada argumentativa do filósofo, assim como avaliar se McDowell tem à disposição recursos conceituais para esquivar-se às críticas.

Para isso, contamos com a seguinte estrutura de texto: primeiro reconstruiremos em detalhe a posição de McDowell acerca da experiência perceptual tal como ela foi exposta em AMG; em seguida reconstruiremos e aprofundaremos os argumentos de Corti (2017) acerca da possibilidade de que a nova posição de McDowell implique no surgimento de uma "ansiedade pluralista"; ao final discutiremos se é possível fornecer uma interpretação da posição de McDowell que ofereça uma saída para tal ansiedade.

\section{A visão revisada de McDowell acerca da experiência perceptual em Avoiding the Myth of the Given}

Qual é a relação entre o conteúdo de um juízo de percepção, tal como "Estou vendo um pintassilgo", e a experiência perceptual que dispõe um determinado sujeito a proferir tal juízo?

Segundo McDowell, a relação entre experiência e juízos não pode ser meramente causal. Isso porque McDowell visa preservar a função justificativa da experiência com relação aos juízos e não entende que a relação causal acomoda a dimensão normativa da justificação. Ainda, segundo o autor, o conteúdo da experiência, para que tenha uma função justificativa com relação aos juízos, não pode ser não-conceitual, pois McDowell concebe o espaço da justificação como co-extensivo ao espaço dos conceitos.

Estas teses negativas já estavam presentes em MM e não se modificaram em AMG. Porém, em MM, o autor entende que a tematização do conteúdo proposicional da experiência é a única alternativa tanto à concepção causal da experiência, como à ampliação do espaço da justificação para além do espaço dos conceitos. Já em AMG, McDowell assume outro posicionamento, pois afirma que o conteúdo da experiência possui uma forma conceitual, mas não proposicional. "O conteúdo discursivo é articulado. O conteúdo intuicional não é." (AMG, p.6, tradução nossa). ${ }^{2}$ 
Para tornar esta posição inteligível é necessário considerar a visão de McDowell no que diz respeito à maneira como nossas capacidades conceituais informam nossa vida epistêmica. Segundo o autor, essas capacidades conceituais podem ser: a) exercidas ativamente na articulação discursiva em forma de juízos e b) operativas passivamente na recepção do conteúdo empírico. ${ }^{3}$ Assim, como já sustentado em MM, McDowell entende que o conteúdo da experiência é conceitual no sentido b). No entanto, em MM, a operatividade passiva de capacidades conceituais resulta no conteúdo proposicional da experiência, o que não ocorre em AMG. Resta saber mais precisamente de que maneira essas capacidades conceituais são operativas passivamente na recepção do conteúdo empírico.

Destarte, chegamos ao que McDowell coloca como segunda afirmação: ii) o conteúdo da experiência não necessariamente inclui tudo aquilo que a experiência permite que o seu sujeito conheça de maneira não inferencial. Por exemplo, quando eu afirmo que "Este é um pintassilgo", formulo um juízo cognoscitivo não inferencial baseado na experiência. O conteúdo da experiência em que o meu juízo se baseia não deve conter tudo aquilo que é expresso no juízo. Isso é, quando eu afirmo que "Este é um pintassilgo", porque vejo um pintassilgo, o conceito de "pintassilgo" não precisa fazer parte do conteúdo da minha experiência.

Alguns conceitos que figuram no conhecimento proporcionado por uma experiência podem ser excluídos do conteúdo da própria experiência, como tenho ilustrado com o conceito de pintassilgo, mas nem todos podem. (AMG, p.4, tradução nossa).

Essa citação pode ser interpretada de duas maneiras diferentes: ela pode significar que o conceito de pintassilgo nunca faz parte do conteúdo da experiência, como também pode significar que o conceito de pintassilgo não faz parte do conteúdo da experiência se um sujeito não possui o conceito de pintassilgo, mas pode fazer parte do conteúdo da experiência caso o sujeito possua o conceito de pintassilgo.

A interpretação correta da posição de McDowell parece ser a primeira. Os conteúdos das experiências, respectivamente, de um sujeito $X$, que possui o conceito de pintassilgo, e de um sujeito $Y$, que não possui o conceito de pintassilgo, não são diferentes pelo fato de o sujeito $X$ possuir tal conceito e de o sujeito $Y$ não. No caso do sujeito $X$, a capacidade recognitiva (recognitional capacity) ${ }^{4}$ do sujeito em questão subsome o conteúdo da experiência sob o conceito "pintassilgo" - o sujeito $X$ reconhece (não-inferencialmente) aquele conteúdo como sendo um pintassilgo. No caso do sujeito $Y$, a capacidade recognitiva do sujeito em questão não subsome o conteúdo da experiência sob o conceito "pintassilgo", pois ele não o possui.

Portanto, o conceito "pintassilgo" não precisa ser visto como sendo parte do conteúdo da experiência de um determinado sujeito, independentemente do fato de o 
sujeito possuir ou não tal conceito. Porém, isso não significa que o conteúdo da experiência possa ser constituído independentemente da operatividade de pelo menos alguns conceitos.

Mas então, quais são os conceitos operativos na constituição do conteúdo empírico da minha visão do pintassilgo?

Um limiar natural (A natural stopping point), para experiências visuais, seriam os sensíveis próprios da visão e os sensíveis comuns acessíveis à visão. Deveríamos conceber a experiência como recorrendo a capacidades conceituais associadas a conceitos de sensíveis próprios e comuns. (AMG, p.4, tradução nossa. $)^{5}$

Assim sendo, o conteúdo da experiência de um pintassilgo é constituído por conceitos tais como cor, "figura, dimensão, posição, movimento ou ausência deste" (AMG, p.5, tradução nossa), etc., e o conceito de animal (sob o qual é compreendido o conceito de pintassilgo) capta a unidade que constitui a forma dos elementos percebidos, mesmo que ele não seja parte do conteúdo da experiência perceptual. ${ }^{6}$

O conceito de um pássaro, assim como o conceito de pintassilgo, não precisa ser parte do conteúdo da experiência [...]. Mas talvez possamos dizer que ele me é dado em tal experiência que aquilo que eu vejo é um animal - não é algo que eu conheço aplicando uma capacidade conceitual sobre àquilo que eu de qualquer modo vejo. Isso não porque "animal" expressa parte do conteúdo unificado na experiência de acordo com uma certa forma de unidade intuicional (AMG, p.5, tradução nossa).

Há, portanto, duas maneiras em que as capacidades conceituais são operativas passivamente na recepção do conteúdo empírico:

- Há conceitos que compõem o conteúdo perceptual — conceitos de sensíveis próprios e comuns;

- Há conceitos que captam a forma categorial do conteúdo intuicional sem por isso ser parte do conteúdo (a forma categorial do conteúdo é captada mediante uma subsunção do conteúdo sob um conceito; tal subsunção é possibilitada pelas capacidades recognitivas do sujeito em questão). McDowell denomina esta unidade de "unidade intuicional" - ex.: "este pintassilgo".

Considerando essas duas maneiras de entender a operatividade das capacidades conceituais na receptividade, cabe perguntar então como passamos do nível da intuição para o nível do juízo, nível em que o conteúdo é articulado discursivamente. A solução de McDowell admite duas modalidades para essa passagem. ${ }^{7}$ 
( $\alpha$ ) A primeira modalidade consiste na explicitação discursiva de parte do conteúdo que já está na intuição, como constituinte do conteúdo dela. McDowell descreve essa passagem da unidade da intuição para a unidade do juízo como uma operação de "recorte" (carving out) de parte do conteúdo intuicional. O recorte do conteúdo intuicional se torna assim um conteúdo articulado. No caso do nosso exemplo do pintassilgo, recortamos parte do conteúdo da intuição e o tornamos explícito na atividade discursiva: "Isto [i.e., o pintassilgo] tem esta determinada matiz de cor", ou, para o caso de termos um conceito adequado para a matiz de cor do pintassilgo em questão, "Isto [i.e., o pintassilgo] é amarelo".

$(\beta)$ A segunda modalidade consiste na subsunção, por meio das nossas capacidades recognitivas, de um conteúdo intuicional sob um determinado conceito unificador. Neste caso, temos a transição da forma discursivamente não articulada do conteúdo recognitivo (por exemplo, "este pintassilgo"), que capta a unidade categorial do conteúdo intuicional, mesmo não sendo propriamente parte do conteúdo intuicional, para a forma discursivamente articulada do conteúdo recognitivo (por exemplo, "este é um pintassilgo"). ${ }^{8}$

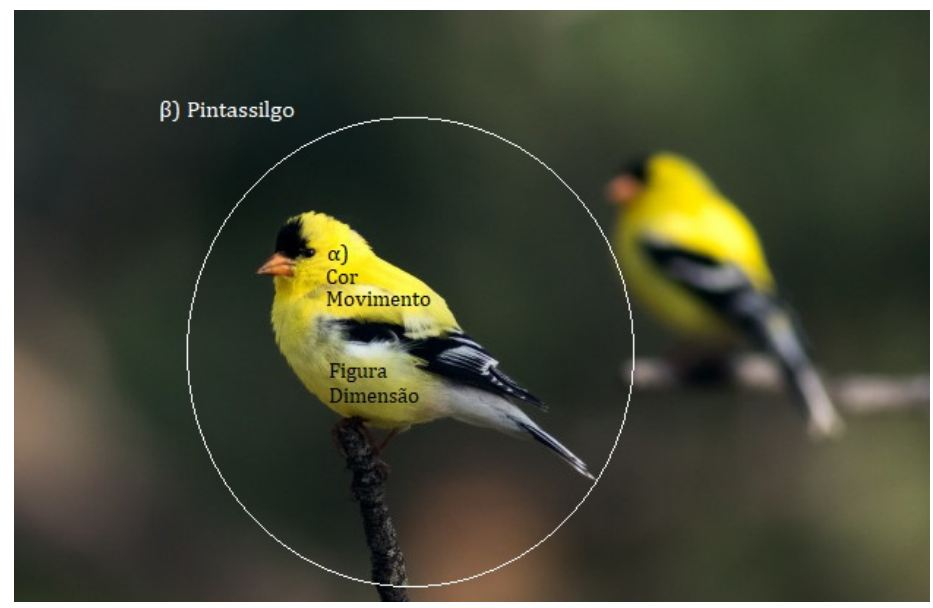

$\alpha$ ) Recorte de um aspecto que é parte do conteúdo da intuição.

- Cor amarela = nível intuitivo

- "Isto é amarelo" = nível discursivo

$\beta$ ) Explicitação da forma categorial da intuição.

- "Este pintassilgo" = nível intuitivo

- "Este é um pintassilgo" ou "Isto é um pintassilgo amarelo" = nível discursivo 


\section{A ansiedade pluralista}

Em um artigo de 2017, Luca Corti levanta a possibilidade de que a nova posição de McDowell acerca da experiência perceptual dê origem a uma ansiedade pluralista. ${ }^{9} \mathrm{~A}$ exposição do argumento de Corti é muito densa e é preciso destrinchá-la para poder avaliar o seu potencial crítico.

De fato, discutindo a possibilidade do surgimento de uma ansiedade pluralista, Corti destaca uma série de problemas que parecem permitir uma categorização conforme os polos de uma oscilação semelhante àquelas que McDowell quer dissolver.

Polo A DA oscilação: Por um lado, Corti parece indicar a possibilidade de que a nova posição de McDowell recaia, a seu malgrado, em uma espécie de Mito do Dado.

Problema 1: "Essa ideia de um conteúdo intuitivo não articulado surpreende o leitor [...]: dados estes pressupostos, como não argumentar que a intuição torna-se a noite em que todas as vacas são negras?" (Corti 2017, p.61, tradução nossa).

Polo B DA oscilação: Por outro lado, Corti parece destacar dois problemas derivados de uma interpretação da posição de McDowell, que sublinha a "integração radical entre conceitos e intuições, que se combinam quando o mundo aparece para nós" (Corti 2017, p.61, tradução nossa).

Problema 2: Tal integração radical, segundo Corti, "repropõe [uma] ansiedade pluralista: quantos modos existem de "recortar"a mesma intuição?" (Corti 2017, p.61, tradução nossa).

Problema 3: Como consequência do pluralismo de recortes, surgiria um problema de hierarquia: "por que preferir a conceituação discursiva por meio de um determinado esquema e não por outro?" (Corti 2017, p.61, tradução nossa).

Na nossa opinião, esta formulação dos problemas ligados ao possível surgimento de uma ansiedade pluralista pode ser refinada - e isso é o que pretendemos fazer em seguida. Para tanto, devemos dirigir a atenção ao trecho de Robert Pippin (2007) que Corti cita para elucidar o Problema 2 e o Problema 3:

As consequências e as criticidades desta escolha [a escolha de uma integração radical entre conceitos e intuições, N. dos A.] são bem explicitadas por um exemplo de Robert Pippin, quando ele afirma que, assim que argumentamos que um certo aparato conceitual está sempre operativo em toda receptividade sensível, então 'será muito difícil continuar a apoiar o ponto de vista do senso comum, segundo o qual antigos escravos gregos e programadores de computador de hoje devem, ter, em alguma camada, um mundo perceptual comum quando admiram o mar Egeu — um mundo 'controlado pelos objetos' vistos da mesma maneira. Quem vive num mundo animado por forças naturais intencionais 'vê' seus efeitos; para quem vive numa comunidade ou 
numa ordem feudal, existem propriedades visíveis e hereditárias, transmitidas pelo sangue, que legitimam uma família a governar por muitas gerações; quando há uma Grande Cadeia do Ser, suas ordens de realidade são diretamente manifestadas a todos aqueles que "têm olhos para ver"; quando as almas reencarnam, os efeitos podem ser percebidos em toda parte; alguém "vê"" a alma [...] e assim por diante [...]. Este é o preço a pagar por "confundir os limites" entre conceito e sensibilidade. (Corti 2017, p.62, tradução nossa; o trecho citado é Pippin 2007, p.425).

Corti, considera tal citação como uma explicitação dos Problemas 2 e 3 . No entanto, podemos identificar nessa passagem um problema adicional — não identificado ou não explicitado por Corti e, de certa forma, "fundido" com o Problema 2. A fim de explicitar tal problema, temos que reformular o PROBLEMA 2 de modo mais preciso.

Corti, de fato, expressa o PROBLEMA 2 perguntando "quantas maneiras existem de 'recortar' a mesma intuição?”. Tal formulação mostra-se enganosa, pois o problema que Corti parece querer apontar não diz respeito à $\alpha$ ) atividade de carving out discursiva de algo que já está lá na intuição como parte do conteúdo dela, mas sim à modalidade $\beta$ ) de passar de um conteúdo intuicional para um conteúdo proposicionalmente articulado, isso é, a explicitação discursiva da subsunção, por meio das nossas capacidades recognitivas, de um conteúdo intuicional sob um determinado conceito unificador ${ }^{10}$. Mas, como vimos, McDowell usa o conceito de "recortar" (carving out) apenas para a modalidade $\alpha$ ).

Por esse motivo, o PROBlEMA 2 pode ser reformulado de modo mais preciso como o Problema 2*.

Problema 2*: o problema da subsunção de um mesmo conteúdo intuicional sob diferentes conceitos unificadores que não são parte constitutiva do conteúdo da intuição. $^{11}$

Deste problema temos que distinguir um problema diferente, que pode ser inferido da citação de Pippin e que está de certa forma "oculto" na imprecisão terminológica da formulação de Corti do Problema 2. Podemos considerá-lo como o PROBLEMA $4 .^{12}$

O Problema 4 levanta a possibilidade de um pluralismo relativo aos conjuntos de conceitos de sensíveis próprios e comuns tornados operativos na recepção do conteúdo intuicional. Dado que os conceitos de sensíveis próprios e comuns fazem parte do conteúdo intuicional, surge aqui a possibilidade de que sujeitos tornem operativos conceitos de sensíveis próprios e comuns diferentes. Nesse caso, tais sujeitos teriam intuições com conteúdos diferentes.

Em outras palavras: a questão presente no PROBLEMA 4 não diz respeito à unificação categorial dos conteúdos intuicionais. A questão é se realmente temos um único mundo intuicional compartilhado, se nossos conteúdos intuicionais são estruturados pelos mesmos conceitos de sensíveis próprios e comuns. 


\section{A posição de McDowell gera efetivamente uma ansiedade pluralista?}

Tendo identificado quatro possíveis problemas para a posição de McDowell a partir da reconstrução de Corti (2017), podemos passar agora a examinar se McDowell possui recursos conceituais para dissipá-los.

O problema de uma possível recaída no Mito do Dado (PROBLEMA 1), pertencente àquele que temos chamado o POLO A DA OsCILAÇÃO, não está diretamente vinculado a uma acusação de pluralismo ansiógeno e não parece atingir a posição de McDowell. ${ }^{13}$ De fato, McDowell afirma claramente que considerar o conteúdo da intuição como não tendo uma forma proposicional não implica em retirar dele a forma conceitual, como ele indica na citação a seguir:

Devemos concluir que as capacidades conceituais não são operativas em ter objetos visualmente presentes, mas apenas naquilo que alguém faz daquilo que ele vê independentemente, de qualquer maneira? Devemos abandonar a própria ideia de que experiências perceptuais tidas por animais racionais possuem conteúdo conceitual?

Isto seria demasiado drástico. Nada daquilo que tenho dito acerca das capacidades recognitivas remove o argumento segundo o qual, sob a pena de cair no Mito do Dado, as capacidades que pertencem à faculdade cognitiva superior têm que recorrer a capacidades conceituais. Alguns conceitos que figuram no conhecimento proporcionado por uma experiência podem ser excluídos do conteúdo da própria experiência, na maneira que tenho ilustrado com o conceito de pintassilgo, mas não todos podem. (AMG, 4, tradução nossa) $)^{14}$

Vamos passar agora a considerar o POLO B DA OSCILAÇÃO: as dificuldades agrupadas nesse lado dizem respeito mais diretamente ao surgimento de uma ansiedade pluralista e têm sua raiz na tese da integração de conceitos e intuições na experiência perceptual. Podemos distinguir, aqui, dois conjuntos problemáticos: o primeiro, que podemos chamar de "problema da unificação do conteúdo intuicional" (ProblemA $2^{*}$ e Problema 3), e o segundo, que se refere à pergunta se temos todos as mesmas intuições (PROBLEMA 4).

No primeiro conjunto problemático, estamos postulando que o mesmo conteúdo intuicional está se apresentando para dois sujeitos, S1 e S2, e se levanta a possibilidade de que ele possa ser unificado pelos sujeitos S1 e S2 segundo conceitos diferentes (Problema $2^{*}$ ). Esse pluralismo das unificações categoriais do conteúdo intuicional geraria como consequência um subproblema (PROBLEMA 3): "por que preferir a conceituação discursiva por meio de um determinado esquema e não por outro?".

Tais problemas não parecem representar necessariamente dificuldades para a posição de McDowell. Ele poderia dizer que o pluralismo veiculado pelo ProBlEMA 2* 
e o consequente PROBLEMA 3 não constituem ameaças ansiógenas na medida em que tal pluralismo se mostra compatível com a posição realista de McDowell acerca do conhecimento empírico ${ }^{15}$ e com seu requisito de um vínculo racional do mundo sobre a nossa experiência. ${ }^{16}$

O espaço para uma tal conciliação nos parece garantido em virtude da "metafísica minimal" de inspiração fregeana defendida por McDowell e de sua relação com a visão mcdowelliana acerca da experiência do mundo externo.

I) De fato, a concepção mcdowelliana da realidade, segundo a qual objetos espaço-temporais não conceituais se manifestam para os sujeitos segundo maneiras de apresentação conceituais na intuição, deixa aberta a possibilidade de diferentes conceituações categoriais da realidade tal como ela se apresenta na experiência. Portanto, objetos espaço-temporais situados no reino da referência podem ser categorizados conceitualmente, de forma diferente, na medida em que se apresentam aos sujeitos segundo sentidos "categoriais" diferentes, sem que isso implique que se perca a ideia de um mundo perceptual compartilhado, pois conceitos de unificação categorial não são parte do conteúdo da intuição (ver seção 2).

II) Esta metafísica minimal, aberta ao pluralismo das unificações categoriais dos conteúdos intuitivos, é compatível com uma versão robusta de realismo - segundo a qual, quando percebemos corretamente (unificando corretamente o conteúdo intuicional), estamos em contato direto com a realidade. Mais em particular, essa posição é compatível com o requisito mcdowelliano do vínculo exercido pelos objetos na experiência.

III) Ao mesmo tempo, a compatibilidade entre pluralismo das unificações conceituais e realismo epistemológico pode dissolver o PROBLEMA 3. Se, por um lado, é preservada a distinção entre unificações categoriais corretas e incorretas, dependendo se elas captam aspectos reais de como as coisas são, por outro, abandona-se a necessidade de estabelecer uma hierarquia entre unificações categoriais corretas, embora diferentes. A tese de que McDowell poderia aceitar essa coexistência nãohierárquica de perspectivas corretas acerca do mundo nos parece corroborada pela apreciação mcdowelliana tanto do ponto de vista da ciência quanto do ponto de vista do senso comum. ${ }^{17,18}$

No que diz respeito ao PRoblema 4, as coisas nos parecem mais complicadas, pois se levanta a possibilidade de que dois sujeitos, $S 1$ e $S 2$, colocados frente ao mesmo objeto (ou melhor: frente à mesma porção de realidade), tenham diferentes conteúdos intuicionais - isto é, percebam conteúdos diferentes na medida em que tornam operativos diferentes conceitos de sensíveis próprios e comuns na recepção do conteúdo. Este problema parece estar vinculado a uma premissa que Corti atribui a McDowell, isso é, a negação de "que existe um conjunto de conceitos universais e a priori que entram na experiência" (Corti 2017, p.62, tradução nossa). Com efeito, a existência de tais conceitos não é explicitada em AMG, portanto é preciso avaliar 
as alternativas à disposição de McDowell para lidar com esse problema a partir do contexto mais amplo das suas visões sobre consciência perceptual.

Alternativa 1: McDowell poderia sustentar que, sim, há um conjunto de conceitos universais e a priori, conceitos de sensíveis próprios e comuns fundamentais tais como "figura, dimensão, posição, movimento ou a sua ausência" (AMG, p.5, tradução nossa), que entram na experiência. Essa alternativa não parece plausível, pois McDowell critica a distinção entre conceitos puros (a priori) e conceitos empíricos (a posteriori). ${ }^{19}$ Tal crítica pode ser extraída da leitura que McDowell faz da passagem da Dedução Transcendental kantiana para a ideia hegeliana de um "livre autodesenvolvimento do "Conceito"' (HWV, p.47, tradução nossa). Com efeito, em ensaios como Self-Determining Subjectivity and External Constraint e Hegel's Idealism as Radicalization of Kant, McDowell mostra como Hegel apaga a distinção entre conceitos a priori e conceitos empíricos - e, portanto, evita o problema de ter que explicar como os conceitos a priori se relacionariam com os conceitos empíricos (cf. HWV, 86). Ademais, para McDowell, todos os conceitos são revisáveis. ${ }^{20}$ Falar em conceitos a priori, portanto, não encontra um lugar no pensamento do McDowell — mesmo se tais conceitos (diferentemente dos conceitos a priori de Kant) fossem conceitos que possuíssem um conteúdo empírico, assim como os conceitos de sensíveis próprios e comuns. $^{21}$

Alternativa 2: McDowell poderia considerar os conceitos de sensíveis próprios e comuns tais como cor, "figura, dimensão, posição, movimento ou a sua ausência" não como sendo a priori, mas como sendo de fato universais. Essa posição nos parece frágil e conduz diretamente à terceira alternativa, a qual nos parece a mais plausível.

Alternativa 3: McDowell admitiria a possibilidade da perda de um mundo perceptual compartilhado. Se todos os conceitos são passíveis de revisão, por que não podemos admitir a possibilidade de formas de vida que possuem um conjunto de conceitos de sensíveis próprios e comuns distinto daquele que possuímos e que tornam tais conceitos operativos na recepção do conteúdo empírico?

Como exemplo, podemos conceber seres humanos que desenvolvem conceitos de sensíveis próprios e comuns diferentes dos nossos, ainda que possuindo os mesmos órgãos de sentido. Ou ainda, seres racionais que possuem uma ou mais capacidades sensoriais que não possuímos, informadas por conceitos que não possuímos. ${ }^{22}$

Para acomodar estes casos, McDowell poderia fazer o movimento de ampliar o seu conjunto de visões e tentar, ainda assim, defender a ideia de um vínculo racional oferecido por experiências de uma mesma porção de realidade (talvez não caiba aqui nos referir a objetos), embora tais experiências sejam diferentes na medida em que seu conteúdo intuicional é constituído por conceitos de sensíveis próprios e comuns diferentes. 
Neste caso, porém, a porção de realidade em questão seria, pelo menos em princípio, percebida de maneira diferente - isto é, teríamos um vínculo racional exercido pela realidade a partir de experiências diferentes. ${ }^{23}$ Os sujeitos S1 e S2 não estariam apenas unificando, segundo formas conceituais diferentes, o mesmo conteúdo intuicional, constituído mediante a operatividade dos mesmos conceitos de sensíveis próprios e comuns (Problema $2^{*}$ ). A operatividade de diferentes conceitos de sensíveis próprios e comuns na recepção do conteúdo intuicional faria com que os dois sujeitos estivessem efetivamente percebendo conteúdos diferentes.

Isso constitui uma fonte de ansiedade para McDowell? Embora a questão resulte particularmente complexa, entendemos que não. Pois admitir a possibilidade de que outros sujeitos racionais, pertencentes a outras formas de vida e dotados de capacidades sensoriais diferentes das nossas, tornem operativos conceitos de sensíveis próprios e comuns diferentes dos nossos e, portanto, tenham intuições diferentes das nossas, não enfraquece a ideia de que os objetos dos quais nós temos experiência segundo os nossos conceitos de sensíveis próprios e comuns sejam um vínculo racional e objetivo para os nossos juízos e que exerçam este vínculo através da experiência. Mesmo admitindo esta eventualidade, McDowell pode manter as ideias centrais da sua visão da relação entre pensamento perceptual e realidade, a saber: I) a ideia de uma realidade espaço-temporal aberta a uma pluralidade de diferentes conceituações (neste caso, não conceituações categoriais, como no caso do Problema 2*, mas conceituações das partes do conteúdo intuicional!), sem que III) haja hierarquias entre as maneiras de conceituação e II) a ideia de um realismo ligado a um vínculo exercido pela realidade na experiência.

O fato de que para nós seja impossível dar um conteúdo mais determinado à mera ideia de conceitos de sensíveis próprios ou comuns que não possuímos, ${ }^{24}$ atrelados a capacidades sensoriais que não possuímos, não é uma boa razão para excluir sua possibilidade em outros seres. A existência de tais formas de vida, porém, é uma questão de facto - uma questão que, portanto, não constitui um problema transcendental que afeta o modo de nos entendermos responsivos ao pensamento empírico.

Em outras palavras: esta forma de pluralismo não é necessariamente ansiógena, porque ela é capaz de ampliar as possibilidades de pensar o mundo como sendo um vínculo racional também para o pensamento de formas de vida que, na constituição do conteúdo intuicional, tornam operativos conjuntos de conceitos de sensíveis próprios e/ou comuns em parte ou mesmo totalmente diferentes dos nossos. ${ }^{25}$ Neste cenário, os nossos conceitos de sensíveis próprios e comuns, tais como cor, "figura, dimensão, posição, movimento ou a sua ausência" continuam possuindo um alcance objetivo: o alcance objetivo da nossa experiência não parece resultar ameaçado pela ampliação das possibilidades de modos de experienciar. 


\section{Considerações finais}

Neste artigo analisamos a versão revisada de McDowell acerca da experiência perceptual, tal como ela tem sido exposta em AMG.

Na seção 2 expusemos como, segundo esta nova visão, o conteúdo da experiência não é proposicional, mas sim conceitual, no sentido em que nele são operativos conceitos de sensíveis próprios e comuns, tais como cor, "figura, dimensão, posição, movimento ou a sua ausência". Tal conteúdo é unificado por conceitos (também operativos em forma passiva e dados na própria receptividade) que captam a forma categorial do conteúdo - tais conceitos não fazem parte do conteúdo e não operam uma articulação deste.

Essa unidade intuicional pode ser articulada discursivamente de duas maneiras: $\alpha$ ) através da explicitação discursiva de algo que já está lá na intuição como parte do conteúdo dela; ${ }^{26} \beta$ ) através da explicitação discursiva da subsunção de um conteúdo intuicional ("estruturado" por conceitos de sensíveis próprios e comuns) sob um determinado conceito unificador. ${ }^{27}$

Na seção 3, a partir da análise de Corti (2017), identificamos 4 possíveis problemas, três dos quais (isto é: os Problemas $2^{*}, 3$ e 4) dizem respeito à possibilidade do surgimento de uma ansiedade pluralista e, portanto, são considerados relevantes para nosso exame. Na seção 4, dividimos os Problemas 2*, 3 e 4 em dois conjuntos problemáticos.

No primeiro, se postula que um mesmo conteúdo intuicional se apresenta para dois sujeitos, $S 1$ e $S 2$, e se levanta a possibilidade de que tal conteúdo possa ser unificado pelos dois sujeitos segundo conceitos diferentes (Problema $2^{*}$ ). Deste problema decorreria o problema de estabelecer uma hierarquia entre diferentes maneiras de unificar e articular os mesmos conteúdos intuicionais (Problema 3). Argumentamos que tais problemas não constituem uma ameaça ansiógena para a posição de McDowell. As consequências teóricas do Problema $2^{*}$, de fato, são perfeitamente compatíveis com outros aspectos da visão global de McDowell: I) a "metafísica" mcdowelliana de uma realidade espaço-temporal não conceitual que se manifesta aos sujeitos segundo maneiras de apresentação conceituais abre à possibilidade de diferentes conceituações categoriais da realidade; além disso, II) tal pluralismo é perfeitamente compatível com o realismo e, mais em particular, com o requisito mcdowelliano do vínculo exercido pelos objetos na experiência. Logo, o PROBLEMA 2* pode ser acomodado na visão global de McDowell de um modo que não justifica o surgimento de qualquer tipo de ansiedade. Este acomodamento dissolve o problema de estabelecer hierarquias entre as maneiras de conceituação do mundo (Problema 3).

No segundo conjunto problemático (Problema 4), levanta-se a possibilidade de que dois sujeitos, $S 1$ e $S 2$, percebam conteúdos diferentes na medida em que tornam operativos diferentes conceitos de sensíveis próprios e comuns na recepção do con- 
teúdo empírico. Após considerar alguns possíveis movimentos teóricos que McDowell poderia fazer para resolver esta dificuldade (ALTERNATIVAS 1, 2, e 3), temos sugerido que McDowell - em virtude da sua recusa a admitir a existência de conceitos de sensíveis próprios e comuns a priori - deveria aceitar a ideia de que os sujeitos $S 1$ e $S 2$ percebem a realidade de modo diferente na medida em que tornam operativos diferentes conceitos de sensíveis próprios e comuns na recepção do conteúdo empírico (ALtERnATIVA 3).

O cenário teórico que se gera se postularmos dois sujeitos que possuem (e tornam operativos na recepção do conteúdo) diferentes conjuntos de conceitos de sensíveis próprios e comuns ainda não contradiz os plexos centrais da visão de McDowell. Com efeito, a realidade permanece como sendo o espaço de justificativa para o pensamento empírico dos sujeitos em questão e suas intuições continuariam sendo aquilo que é articulado discursivamente por eles. De tal modo, a visão revisada da experiência perceptual oferecida por McDowell nos fornece um marco teórico e recursos conceituais que evitam que o pluralismo decorrente dela se torne ansiógeno.

\section{Referências}

Burge, T. 2003. Perceptual Entitlement. Philosophy and Phenomenological Research 67: 503548.

Connolly, K. 2014. Which Kantian Conceptualism (or Nonconceptualism)? The Southern Journal of Philosophy 52(3): 316-337.

Corti, L. 2017. La terapia incompleta di John McDowell: ansie pluraliste e ansie storiche. In L. Corti \& G. Miolli (org.), Hegel e McDowell. Esperienza, verità, normatività, pp.49-67. Padova: Verifiche.

Dupré, J. 1993. The Disorder of Things. Metaphysical Foundations of the Disunity of Science. Cambridge, Mass.: Harvard University Press.

El Kassar, N. 2015. Towards a Theory of Epistemically Significant Perception. How We Relate to the World. Berlin: DeGruyter.

Lauer, David. 2014. Offenheit zur Welt. Die Auflösung des Dualismus von Begriff und Anschauung. In Ch. Barth \& D. Lauer (orgs.), Die Philosophie John McDowells, pp.37-62. Muenster: Mentis.

McDowell, John. 2005 [1996]. Mente e Mundo [MM]. Trad. J. V. Gallerani Cuter. São Paulo: Ideias e Letras.

McDowell, John. 2008. Avoiding the Myth of the Given [AMG]. In J. Lindgaard (org.), John McDowell: Experience, Norm, and Nature, pp.1-14. Oxford, UK: Blackwell.

McDowell, John. 2009. Having the World in View: Essays on Kant, Hegel, and Sellars [HWV]. Cambridge MA: Harvard University Press.

McDowell, John. 2018. Travis on Frege, Kant and the Given. In J. Gersel et al. (orgs.), In the Light of Experience: New Essays on Perception and Reasons, pp.24-36. Oxford: Oxford University Press. 
Philie, Patrice. 2015. Sellars and McDowell on Objectivity. Kriterion - Journal of Philosophy 29(3): 63-92.

Pippin, Robert. 2007. McDowell's Germans: Response to 'On Pippin's Postscript'. European Journal of Philosophy 15(3): 411-434.

Redding, Paul. 2018. Hegel and McDowell on Perceptual Experience and Judgment. In F. Sanguinetti \& A. Abath (orgs.), McDowell and Hegel: Perceptual Experience, Thought and Action, pp.117-132. Switzerland: Springer.

Williams, Michael. 2006. Science and Sensibility: McDowell and Sellars on Perceptual Experience. European Journal of Philosophy 14(2): 302-325.

\section{Notas}

${ }^{1}$ Sobre a mudança de McDowell acerca da visão do conteúdo da experiência cf. Pippin (2007), Lauer (2014), El Kassar (2015), Corti (2017), Redding (2018). A reconstrução analítica de Nadja El Kassar (2015) nos parece ser a mais estendida e detalhada.

${ }^{2}$ Tyler Burge (2003, p.527 e ss.) critica a primeira versão do conceitualismo de McDowell sustentando que a concepção da percepção como sendo proposicional é "implausível" e "empiricamente não suportada". Para Burge, tal concepção implica uma hiper-intelectualização da experiência.

${ }^{3}$ Estes são dois modos distintos de operatividade da mesma capacidade.

${ }^{4} \mathrm{~A}$ capacidade de reconhecimento é aquela que permite que o sujeito esteja na posição de conhecer (de maneira não inferencial) que $p$, a partir de um determinado conteúdo empírico. Tal conteúdo empírico é um conteúdo intuicional (não proposicional) e nele não está presente o conceito sob o qual a capacidade de reconhecimento permite ao sujeito subsumir o que vê. Isso, porém, não significa que a subsunção seja uma atividade exercida pelo sujeito, uma atividade em que o conceito sob o qual o conteúdo é subsumido se aplicaria àquilo que eu de qualquer maneira vejo. A unidade do conteúdo intuicional, captada pelo conceito sob o qual o conteúdo é subsumido, é dada na própria experiência, embora o conceito em questão não seja parte do conteúdo intuicional (cf. página seguinte).

5 "Sensíveis próprios" traduz "proper sensibles", "sensíveis comuns" traduz "common sensibles".

${ }^{6} \mathrm{~A}$ presença de conceitos de sensíveis próprios e comuns no conteúdo da experiência faz com que o conteúdo dado não seja dado de forma mítica. McDowell usa como exemplo de forma categorial de uma intuição o conceito de animal, estendendo a tal conceito a abordagem de Thompson aos conceitos de forma, que são, nas palavras de El Kassar (2015, p.158 - tradução nossa), "conceitos distintos, porque eles possuem uma unidade especial que vem com eles". Mas quais são, para McDowell, as formas categoriais possíveis de uma intuição? El Kassar vê nesse ponto um problema. "O problema com as explanações de McDowell [... ] é que não está claro se podemos estendê-las. Quais outros conceitos formais podemos encontrar? Podemos construir outras formas categoriais ou conceitos formais que funcionam como forma de vida e animal - digamos pássaro, cubo ou casa? Será que há até uma categoria especial para cada objeto [... ] que um sujeito pode perceber? Quão fina é a granularidade das formas categoriais? Pode haver conceitos formais cujas instâncias são entidades não-viventes? Note-se que nós não podemos apenas recorrer às categorias kantianas, porque 
McDowell não quer ter que incluí-las. [... ] A situação de McDowell pode ser enquadrada nos termos de um dilema: ou as suas observações acerca da unidade categorial proporcionada pela categoria animal podem ser facilmente aplicadas a outras categorias - mas neste caso seria menos claro em que constituiria realmente a correspondência especial entre unidade proposicional e unidade intuicional. Ou McDowell insiste que a categoria animal é especial, mas então haveria uma lacuna explanatória, a dizer, surgiriam questões que giram entorno a quais categorias são especiais e porque, etc." (El Kassar 2015, p.166 - tradução nossa). De fato, McDowell não desenvolve esse ponto, mas nos parece que ele propenderia para a primeira alternativa do "dilema" delineado por El Kassar, na medida em que - como veremos (cf. infra, nota 16) - para McDowell esta escolha não implica a geração de um problema de transição entre unidade intuicional e unidade proposicional.

${ }^{7}$ Estas duas modalidades são explicitadas novamente em McDowell (2018).

${ }^{8} \mathrm{McDowell}$ explica este ponto apoiando-se (parcialmente) a Sellars: "[A] experiência [... ] figura em nosso título (entitlement) a formular juízos que podem ir além do conteúdo [de uma intuição, N. dos A.] em modos que refletem capacidades de reconhecer coisas que se apresentam para alguém numa intuição. Mas, como tenho insistido, no próprio intuir não lidamos discursivamente com o conteúdo. Tenho mencionado a proposta de Sellars segundo a qual o conteúdo de uma intuição pode ser capturado, em parte, por um conjunto de palavras tipo 'este cubo vermelho'. O conteúdo expressado desta maneira seria um conteúdo discursivo fragmentário. Ele pode ser parte do conteúdo de um juízo justificado [de tal forma que, N. dos A.] aquilo que alguém julga contém, além do conteúdo da própria intuição, conceitos cujo figurar no juízo reflete capacidades conceituais que são levadas a ser relevantes (bear on) para algo que a intuição apresenta ao sujeito. Assim, um fragmento de discurso que começa com 'Este cubo vermelho ...' pode continuar com '... é aquele que vi ontem'. Eu acho que isto indica que a proposta de Sellars é útil apenas até certo ponto. De fato, ela poderia parecer implicar que o conteúdo intuicional é essencialmente um conteúdo discursivo fragmentário. Mas o conteúdo intuicional não é absolutamente um conteúdo discursivo. Ter algo em vista, digamos um cubo vermelho, pode ser algo completo em si mesmo. Ter algo em vista pode possibilitar uma expressão demonstrativa, ou um análogo no juízo, que alguém pode usar em tornar explícito algo que alguém considera estar assim e assim, mas este potencial não precisa ser atualizado" (AMG, p.11, tradução nossa).

${ }^{9}$ Corti (2017), pp.61-63. A atitude metafilosófica de McDowell visa a dissolver problemas filosóficos junto com as ansiedades anexas de procurar soluções construtivas para eles. Corti não pretende mostrar como a terapia mcdowelliana com relação ao problema da relação entre mente e mundo falha tout court, mas que ela, "embora funcione, pelo menos temporariamente, a nível local (para resolver dificuldades relativas à experiência perceptiva), [...] não é na verdade desprovida de efeitos colaterais. Mesmo dissolvendo alguns problemas, ela de fato abre outros, os quais requerem diagnósticos ulteriores e tratamentos correspondentes" (Corti 2017, p.52, tradução nossa). De certa forma, isso é o que pretendemos fazer com relação ao conjunto de possíveis ansiedades geradas pelo pluralismo.

${ }^{10} \mathrm{O}$ melhor exemplo entre aqueles oferecidos por Pippin e citados por Corti é aquele da percepção do mar. Os outros exemplos parecem menos pertinentes.

${ }^{11}$ Mais uma vez, esta subsunção não deve ser concebida em termos aditivos — veja-se supra, nota 4.

${ }^{12}$ Segundo a nossa interpretação, portanto, tanto Pippin como Corti estão misturando nas 
suas análises dois problemas distintos (isso é, o Problema 2* e o Problema 4) e os estão considerando como um problema único.

${ }^{13}$ Corti parece ciente disso, pois ele discute em maior detalhe o conjunto de problemas que temos agrupado no Polo B DA oscilação, isso é: o conjunto de problemas que surge em virtude de uma "integração radical entre conceitos e intuições, que se combinam quando o mundo aparece para nós" (Corti 2017, p.61, tradução nossa).

${ }^{14}$ Parece, portanto, equivocada a consideração de Kevin Connolly (2014, p.321) segundo a qual a versão revisada da filosofia da percepção de McDowell "deixa margem para a existência de intuições sem conceitos", tradução nossa. Também parecem não atingir o alvo duas críticas formuladas por El Kassar (2015) a este respeito. 1) A primeira é uma crítica à noção de conteúdo intuicional como construto teórico ad hoc (pp. 166-167, tradução nossa): "o conteúdo intuicional parece ser um construto teórico, introduzido para desenvolver uma teoria satisfatória da experiência perceptual que evita o Mito do Dado. [...] O ponto destas observações aqui é o seguinte: se alguém não quer evitar o Mito do Dado, então não precisa introduzir o conteúdo intuicional e não pode nem entender qual é o conjunto de razões para introduzi-lo." Essa crítica, colocada desta forma, parece-nos insuficiente: obviamente, quem não enxerga nenhum Mito na ideia de um conteúdo não-conceitual que possui uma função justificativa não vê a necessidade de postular um conteúdo intuicional conceitual mas não articulado. 2) A segunda crítica problematiza a passagem da forma não articulada da intuição para a forma articulada do juízo (p.168 e ss.). El Kassar observa que há uma discrepância entre a maneira como McDowell trata o conteúdo intuicional nas Woodbridge Lectures de 1997 e em AMG. El Kassar destaca que, nas Woodbridge Lectures, McDowell trata o conteúdo intuicional como "essencialmente um fragmento de conteúdo de juízo" (Having the World in View (HWV), p.35, tradução nossa). Esta consideração do conteúdo intuicional, claramente, não condiz com aquilo que McDowell afirma em AMG, em que McDowell diz que o conteúdo intuicional não é um conteúdo discursivo fragmentário (cf. supra, nota 8). Segundo El Kassar, essa nova concepção joga de novo McDowell na direção de uma concepção do conteúdo intuicional como não-conceitual, tornando assim problemática a transição do conteúdo intuicional inarticulado para o conteúdo articulado dos juízos. Por um lado, esta objeção nos parece não atingir o alvo na medida em que McDowell continua sustentando que o conteúdo intuicional é conceitual all the way down, graças à operatividade de conceitos de sensíveis próprios e comuns. Por outro lado, acreditamos que McDowell responderia que, assim como não precisamos de uma explicação de como os conceitos se referem ao mundo, não precisamos explicar como se dá a articulação discursiva do conteúdo intuicional. Essa transição é problemática apenas para quem defende a tese de que o conteúdo intuicional é não-conceitual.

${ }^{15}$ Por "realismo" entendemos, aqui, uma posição alternativa ao "mero construtivismo", este último sendo definido como a ideia pela qual o nosso conhecimento é construído de uma forma arbitrária (ou melhor: radicalmente social), no sentido de que ele não estaria vinculado pelo modo como a realidade é.

${ }^{16} \mathrm{Cf}$. McDowell (MM, Introdução, §§ 6-8 e Lição II).

${ }^{17} \mathrm{~A}$ posição de McDowell parece, de fato, querer deflacionar o conflito entre "imagem científica" e "imagem manifesta". Acerca deste assunto, ver Williams (2006) e Philie (2015).

${ }^{18}$ Para entender como seja possível conciliar pluralismo das categorizações conceituais e realismo epistemológico, pode ser útil olhar para o projeto de metafísica pluralista de John 
Dupré (1993). John Dupré propõe uma metafísica segundo a qual a realidade é metafisicamente aberta a várias conceituações, uma metafísica que ele chama de 'realismo promíscuo': existem vários padrões reais que podem ser capturados conceitualmente a partir de diferentes interesses. Não queremos aqui identificar a posição de McDowell e a posição de Dupré, pois o foco da investigação dos dois autores não é o mesmo. Mais particularmente, Dupré (pelo que sabemos) não aborda diretamente as questões da relação entre conceitos e conteúdos intuicionais e de como o nosso pensamento é responsivo aos objetos na experiência. Contudo, nos parece que a ideia central de Dupré - se devidamente adaptada ao contexto temático mcdowelliano - pode servir como auxílio analógico para entender nossa proposta interpretativa com relação a McDowell. De modo análogo à posição que achamos que McDowell poderia sustentar para se defender dos Problemas $2^{*}$ e 3 , a perspectiva de Dupré cria espaço para a tese segundo a qual as entidades do mundo podem ser legitimamente categorizadas de forma diferente sem que isso implique que todas as categorizações sejam corretas. Dentre das categorizações corretas, não temos necessariamente porque estabelecer hierarquias entre categorizações da realidade: não há um ponto de vista privilegiado sobre a conceituação da realidade.

${ }^{19} \mathrm{O}$ adjetivo "empíricos" em relação a "conceitos" diz respeito ao conteúdo, não a uma suposta origem dos conceitos por abstração das sensações - cf. HWV, p.26.

${ }^{20} \mathrm{McD}$ owell argumenta, porém, que os conceitos empíricos mais básicos são os menos passíveis de revisão. Cf. MM, p. 49: "Sem dúvida, há pouquíssimas chances de que tenhamos um dia necessidade de remodelar os conceitos nas bordas mais externas do sistema, os conceitos mais imediatamente observacionais, para responder a pressões surgidas no interior do sistema."

${ }^{21}$ Cabe notar que os conceitos a priori, na visão kantiana, não são os conceitos de sensíveis próprios e comuns, mas as categorias.

${ }^{22}$ Este é o ponto que McDowell parece tocar quando considera a possibilidade de marcianos racionais, dotados de capacidades sensoriais diferentes das nossas. Cf. MM, p. 162, nota 11: "É possível que os marcianos tenham uma capacidade de ecolocalização que figure na base racional de sua visão de mundo, do mesmo modo que nossos sentidos figuram na base da nossa. Não preciso negar que pudesse haver conceitos ancorados em capacidades sensoriais tão longínquas das nossas que tais conceitos seriam incompreensíveis para nós."

${ }^{23}$ Portanto, Pippin (2007, p.425) está certo em afirmar que, dado o entrelaçamento de conceitos e sensibilidade, pode se perder a ideia de que haja "um mundo perceptual comum [... ' 'controlado pelos objetos' vistos da mesma maneira." Porém, esta perda se dá apenas para formas de vida que tornam operativos, na recepção do conteúdo sensível, conceitos de sensíveis próprios e comuns diferentes dos nossos. Portanto, o exemplo de Pippin ("aqueles que vivem em um mundo animado por forças naturais intencionais 'veem' seus efeitos [... ]") não nos parece adequado. Na visão de McDowell, aqueles que vivem em um mundo animado por forças naturais intencionais não têm necessariamente um mundo perceptual diferente do nosso, porque o conceito de 'força natural intencional' - assim como o conceito de pintassilgo — não é um conceito de sensível próprio ou comum que constitui os conteúdos intuitivos.

${ }^{24}$ De fato, como o próprio McDowell reconhece, parece-nos que quando tentamos pensar outros conceitos de sensíveis comuns e próprios que não possuímos, alcançamos os limites da nossa forma de vida: para podermos conseguir deveríamos poder "sair da nossa pele".

${ }^{25}$ Uma questão que poderia ser colocada diz respeito a quantos conceitos de sensíveis pró- 
prios e comuns diferentes dos nossos, essas formas de vida devem tornar operativos para que possamos falar de mundo perceptual diferente. Com efeito, a diferença parece ser passível de gradações e este aspecto parece contribuir a amenizar o potencial ansiógeno da objeção em questão (agradecemos um/a parecerista da revista por chamar nossa atenção sobre este aspecto).

${ }^{26}$ Aqui temos o recorte de uma parte do conteúdo intuicional categorialmente unificado que é tornada explícita através da associação com uma capacidade linguística - por exemplo, a cor amarela do pintassilgo é articulada linguisticamente no juízo "este pintassilgo é amarelo".

${ }^{27}$ Aqui temos a passagem da unidade intuicional não articulada "este pintassilgo" para o juízo “este é um pintassilgo".

\section{Agradecimentos}

Agradecemos a Eros de Carvalho, a Roberto Horácio de Sá Pereira, a Davide Dalla Rosa, a Bruno Vaz e aos participantes do grupo GEL da UFRN, por terem comentado versões precedentes deste artigo e a Laísa Trojaike, pela cuidadosa revisão linguística. Um agradecimento especial para Luca Corti, que se disponibilizou a conversar conosco e ofereceu sugestões importantes. Finalmente, agradecemos aos revisores da Principia por terem contribuído com suas observações críticas. 